\title{
Reviewing Treatments for Cocaine Consume Problems: The Gabapentinoid Alternative
}

\author{
Gabriel C Quintero Garzola (D) \\ Department of Psychology, Florida State \\ University - Republic of Panama, Panama \\ City, Republic of Panama
}

Correspondence: Gabriel C Quintero Garzola

Department of Psychology, Florida State University - Republic of Panama, City of

Knowledge, Clayton No. 227, Panama

City, Republic of Panama

Tel +507 3I7-0367

Fax +507 317-0366

Email gquintero@fsu.edu
Background: Cocaine use disorder is a worldwide problem. Presently, however, no adequate treatments exist. Gabapentin has been explored recently as an alternative for treating different substance use disorders, including cocaine.

Methods: The aim of the present paper is to assess the effectiveness of gabapentin for treating cocaine use disorders. For this purpose, a systematic review of the literature was performed using the publication database, PubMed, with search limits from January 1, 1983 to February 28, 2018. The search terms used were combined as follows: "gabapentin" AND "cocaine". Initially, 41 articles were identified, with additional 23 articles identified through reference exploration or web search. These 23 complementary articles relate mainly to the general description of gabapentin and discussion. After the analysis of the titles and abstracts, 18 references were removed, resulting in 46 articles for further analysis.

Results and Discussion: Gabapentin is inadequate for treating cocaine dependence and relapse, and alleviating the subjective effects of cocaine. More research is necessary for exploring gabapentin alleviation of cocaine intoxication, and further investigation is required for confirming the gabapentin's utility for treating cocaine addiction.

Keywords: gabapentin, substance use disorders, stimulants, remedy

\section{Introduction}

Gabapentin is a pharmaceutical drug that has different brand names in the market (Horizant, Neurontin). ${ }^{1}$ It consists of white solid crystals; its molecular weight formula is $\mathrm{C}_{9} \mathrm{H}_{17} \mathrm{NO}_{2}$ (molecular weight: $171.24 \mathrm{~g} / \mathrm{mol}$ ). ${ }^{1}$ In the market, gabapentin can be sold in the forms of tablets (doses of 300, 600 and $800 \mathrm{mg}$ ) or capsules (doses of 100, 300 and $400 \mathrm{mg}$ ) of multiple doses. ${ }^{2}$ Gabapentin has very broad pharmacodynamic and pharmacokinetic properties. ${ }^{3}$

Gabapentin has been explored experimentally in clinical and basic models, ${ }^{4-7}$ and has been used for the treatment of seizures, ${ }^{8,9}$ as well as treating psychiatric disorders and impulsivity, ${ }^{10,11}$ Lou Gehrig's disease, ${ }^{12}$ pain, ${ }^{13,14}$ eagerness, ${ }^{15}$ neuralgia, ${ }^{16}$ Willis-Ekbom disease, ${ }^{17,18}$ and manic depression. ${ }^{19}$ General reviews have described gabapentin for treating psychiatric and substance use disorders, including cocaine. ${ }^{20-27}$ The present study aims to provide an updated review of gabapentin use for alleviating cocaine use disorders. It is also important to consider the use of gabapentin in treating addiction and other health problems that has for the most part of label.

Regarding the effects of gabapentin in the brain, gabapentin is known to bind to the $\alpha_{2} \delta_{1}$ subunit of $\mathrm{Ca}^{2+}$ channels, and affecting $\mathrm{Ca}^{2+}$ currents; ${ }^{25}$ moreover, gabapentin inhibits presynaptic voltage-gated $\mathrm{Na}^{+}$and $\mathrm{Ca}^{2+}$ channels, impeding the 
release of different neurotransmitters, including glutamate. $^{3,20}$ Because $\alpha_{2} \delta_{1} \mathrm{Ca}^{2+}$ channels are found broadly in the nervous system (brain and spinal cord), this could possibly account for the benefit of gabapentin in pain, epilepsy and diverse disorders. ${ }^{25}$ Similar protective effects of gabapentin on animals or in vitro models of CNS hyperexcitability during alcohol withdrawal have been observed. ${ }^{20}$

Drug addiction has been described as diverse maladaptive psychological and behavioral manifestations including: drug intake dyscontrol, taking drugs in larger quantities than planned, repeated failures for decreasing or ceasing drug use, continued drug use despite adverse implications, and the appearance of drug-specific symptoms of tolerance and/or withdrawal. ${ }^{23}$ Also, drug addiction is linked to family breakdown, interpersonal relationships and social dysfunctions, loss of life, and noticeable socioeconomic burdens in society. ${ }^{23}$

Cocaine dependence is a principal public health concern that is characterized by relapse and a cluster of medical, psychological and social problems. ${ }^{21,22}$ Despite decades of clinical trials, there has been no effective pharmacotherapy for cocaine dependence. ${ }^{21,22}$ To treat cocaine dependence in individuals, extensive consideration has been given to optimal pharmacological approaches, and both dopamine antagonists and agonists have been considered. Anticonvulsants have been candidates for use in the treatment of addiction based on the hypothesis that seizure kindling-like mechanisms contribute to addiction. ${ }^{22}$

The present review expands on previous literature recognizing the potential of gabapentin for treating substance use disorders related symptoms ${ }^{24}$ by evaluating the suitability of gabapentin for alleviating cocaine use problems. Indeed, there are a number of advantages in the use of gabapentin to treat cocaine use disorders, including relatively low addiction potential, safe and convenient detoxification course, preserve from withdrawal linked convulsions, and it can be useful for alleviating other comorbid mental health problems. ${ }^{24}$ Based on scientific reports stating that gabapentin may be useful for treating substance use problems, ${ }^{24}$ this review aims to evaluate gabapentin's potential for alleviating problems linked to cocaine use. The purpose of this review is to organize and review the different clinical reports and researches related to human cocaine consume problems (dependence, relapse, subjective effects, and craving); this review also includes complementary rodent research about cocaine consume problems (dependence, relapse, intoxication).
The first contribution of this review is to offer an integrated description of the different clinical works on human cocaine use problems (dependence, relapse, subjective effects, and craving), and it is further complemented with rodent research on cocaine consume problems. Because research reports differ regarding the way gabapentin is applied (alone or combined with other drugs), ranges of treatment doses, time frames of treatments, sample sizes and other variables, different tables were created that consider those different variables. This review allows clinicians and researchers to quickly find the main parameters used in the cocaine reports included here. The second contribution of this review is to offer an updated source regarding the current state of success, failure, inconsistencies, absence or scarcity of studies (human, but also rodent) in the subfield of gabapentin treatment for cocaine consume problems.

\section{Methods}

\section{Inclusion and Exclusion Criteria}

Human (clinical) and non-human (pre-clinical/basic) studies with an experimental or quasi-experimental design that investigated the effect of gabapentin, given alone or in conjunction with other drugs, for treating cocaine use disorders or related issues were included. Articles were required to be mainly experimental, quantitative and/or clinical (but revisions were included for the purpose of the introduction section), describe the number of subjects, and be written in English. Abstracts without full-text articles, conference reports, and non-scientific publications were excluded. The studies included the use of gabapentin alone or in combination with other drugs, published from January 1, 1983, to February 28, 2018.

\section{Inquiry Strategy}

The search was performed from January 1, 1983, to February 28, 2018, using the PubMed database. The keywords used for the search were "gabapentin" AND "cocaine". Initially, 41 articles were obtained from the output of the PubMed database; additionally, further 23 articles were identified through reference exploration or web search. These 23 complementary articles relate mainly to the general description of gabapentin and discussion. After analysis of the title and resume, 18 references were ruled out, resulting in 46 articles for further analysis. After the analysis of the full version of the articles, a total of 46 articles were selected for inclusion 


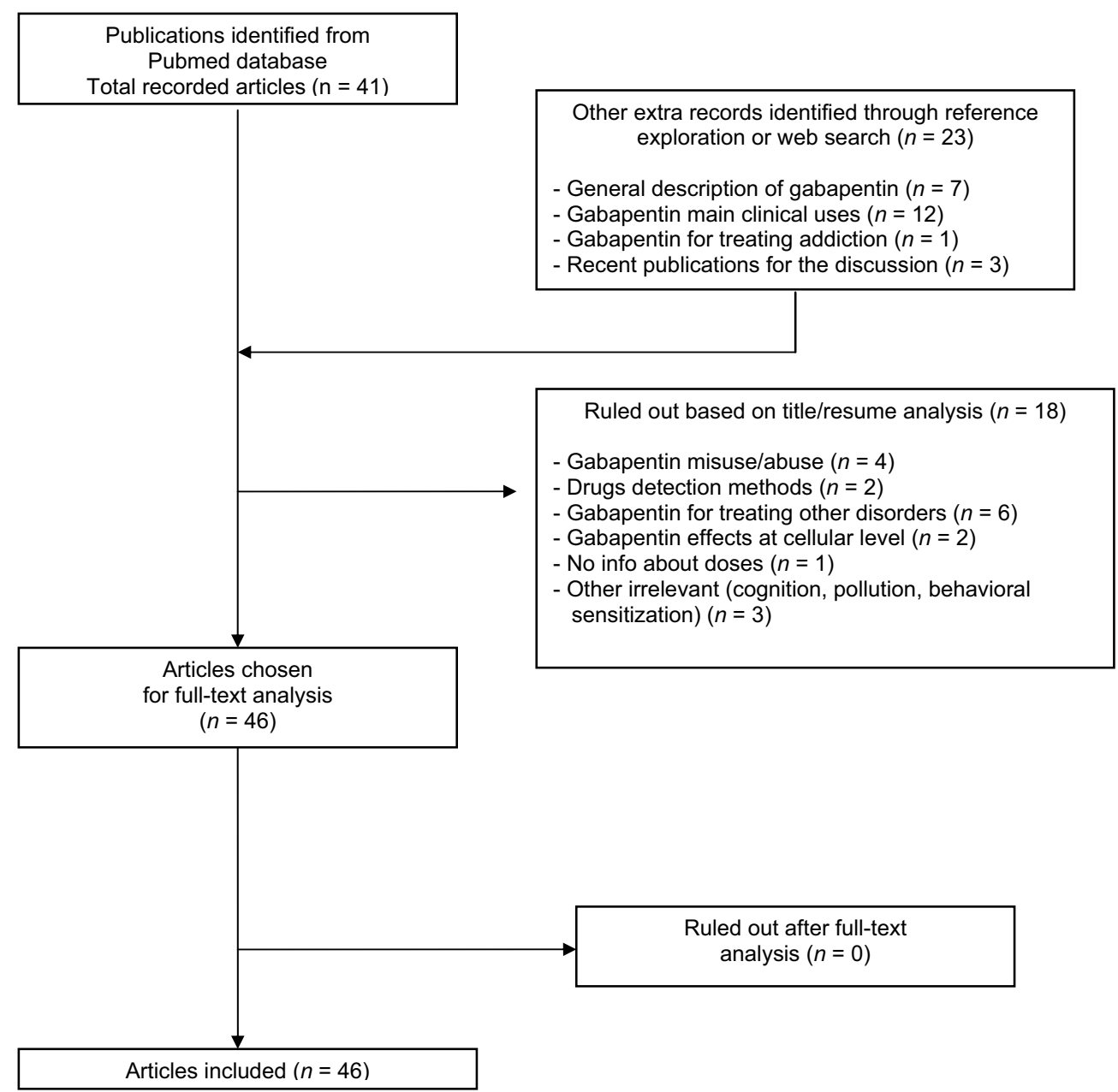

Figure I The diagram illustrates the strategy used for manuscript selection, starting from initial Pub Med database screening, up to the final manuscripts included in the publication.

in the review. Details are described in Figure 1, following PRISMA guidelines.

\section{The Method for Estimating Gabapentin Success in Treating Cocaine Use Problems}

The estimation of success was expressed in percentages. The percentages were calculated by means of the following formula:

$$
\frac{(\# \text { of successful studies })}{\left(\begin{array}{l}
\# \text { of successful studies } \\
+\# \text { of unsuccessful studies }
\end{array}\right)} \times 100=\begin{aligned}
& \% \text { of successful } \\
& \text { studies }
\end{aligned}
$$

This formula was used for calculating the percentage of success. This formula consists of dividing the number of successful studies among the total number of studies carried out (unsuccessful and successful). Subsequently, the result of this division was multiplied by 100 .
A study is considered successful if it meets any of the following conditions:

1. If gabapentin alone (uncombined with other drugs or interventions) was compared to a control group (for example, placebo) only, it performed better than the control condition.

2. If gabapentin combined with other drugs or interventions was compared to a control group only, and the combination performed better than the control condition.

3. If gabapentin uncombined was compared to other drugs and to a control group, then gabapentin performed better than the other conditions.

4. If gabapentin combined with other drugs or treatments were compared to other drugs and to a control group, then the gabapentin combination performed better than the other conditions. 
5. If gabapentin uncombined or combined with other drugs or treatments demonstrated effectiveness for treating a condition, then no control group was included, for example.

\section{Results}

\section{Clinical Studies on the Use of Gabapentin for Treating Cocaine Dependence}

The main points of this section are described in Table 1. Gabapentin was employed in a total of 8 studies between the years 2001 and 2007, with successful result in two out of the eight studies $(25 \%)$.

Gabapentin was used uncombined (alone, without any other drug) in five studies, combined with another drug in one study, and contrasted against other drugs in two studies.

Two out of the five works ( $40 \%$ ) that used gabapentin alone for alleviating cocaine dependence stated successful results. $^{28,29}$ Specifically, these studies used gabapentin doses ranging from $800-2400 \mathrm{mg} / \mathrm{d}$, during 168 days, and $1200 \mathrm{mg} / \mathrm{d}$, during 56 days. The initial sample size used in these studies was in the range of 11 to 30 participants. On the other hand, 3 studies reported gabapentin failure in reducing cocaine use. ${ }^{30-32}$ These studies used a range of doses from 0-3200 mg/d of gabapentin (including placebo groups) during 48 days of treatment; the initial range of sample was six to 15 participants. A possible explanation for the gabapentin failure was the relatively small sample compared to other successful studies.

A single study found that a combination of gabapentin and individual relapse prevention therapy was no better than placebo for treating cocaine dependence. ${ }^{33}$ In this study, a regimen of $3200 \mathrm{mg} / \mathrm{d}$ of gabapentin was used, and the length of the treatment was a total of 84 days. The initial investigation sample was 99 subjects (51 withdrew during the study).

Studies also compared gabapentin against other drugs for treating cocaine dependence, and they generally showed that gabapentin was no better than reserpine, ${ }^{34}$ or tiagabine for reducing cocaine dependence. ${ }^{35}$ Specifically, the first study used a gabapentin dose of $1800 \mathrm{mg} / \mathrm{d}$, a reserpine dose of $0.5 \mathrm{mg} / \mathrm{d}$, a lamotrigine dose of $150 \mathrm{mg} /$ $\mathrm{d}$, and a placebo group. The length of the treatments lapses for a total of 10 weeks. Moreover, the total initial sample was 60 subjects ( 10 retired from the investigation). On the other hand, the second study used a gabapentin dose of $800-2400 \mathrm{mg} / \mathrm{d}$, a tiagabine dose of $4-24 \mathrm{mg} / \mathrm{d}$, and a placebo group (besides, all subjects received methadone treatment). The total duration of the treatments was 10 weeks. The total initial sample was 76 subjects (15 did withdraw from the study).

\section{Clinical Studies on the Use of Gabapentin for Treating Cocaine Relapse}

The main aspects of this section are described in Table 2 . A single study explored the effect of gabapentin in alleviating cocaine relapse, and its result was unsuccessful. ${ }^{36}$ This investigation compared the effectiveness of the combination of gabapentin and sertraline for delaying relapse; it was found that the combination did not surpass sertraline (alone) effectiveness in delaying cocaine relapse. More specifically, the experimental group that was treated with the combination of both drugs received a gabapentin dose of $400-1200 \mathrm{mg} / \mathrm{d}$, and a sertraline dose of $50-200 \mathrm{mg} / \mathrm{d}$ (both during 12 weeks). The other experimental group used only a sertraline dose of 50-200 mg/d, during 12 weeks. The study also included a placebo group. The initial total sample was 99 participants (25 did withdraw from the study).

\section{Clinical Studies on the Use of Gabapentin for Treating Subjective Effects of Cocaine} The main points of this section are provided in Table 3. Gabapentin was employed in a total of four investigations between 2004 and 2007, with successful results in one out of the four studies (25\%). Gabapentin was used alone (without any other drug) in all the studies. One study reported that gabapentin successfully decreased some of the subjective effects of cocaine under a low dose regimen. ${ }^{32}$ The doses applied in this study were 600 and $1200 \mathrm{mg} / \mathrm{d}$ of gabapentin. The treatment lasted 48 days and included a placebo group. The initial sample size was 15 participants with 8 withdrawing from the study. By contrast, the remaining 3 studies reported gabapentin ineffectiveness in reducing subjective effects of cocaine..$^{30,31,37}$ The ranges of doses administered in these studies were $0-3200 \mathrm{mg} / \mathrm{d}$ during 48 days. Placebo groups were included, and the sample sizes ranged from 6 to 15 .

\section{Clinical Studies on the Use of Gabapentin for Treating Cocaine Craving}

The main points of this section are provided in Table 4 . Gabapentin was used in a total of two reports between 1997 and 2000, with both reporting successful results 


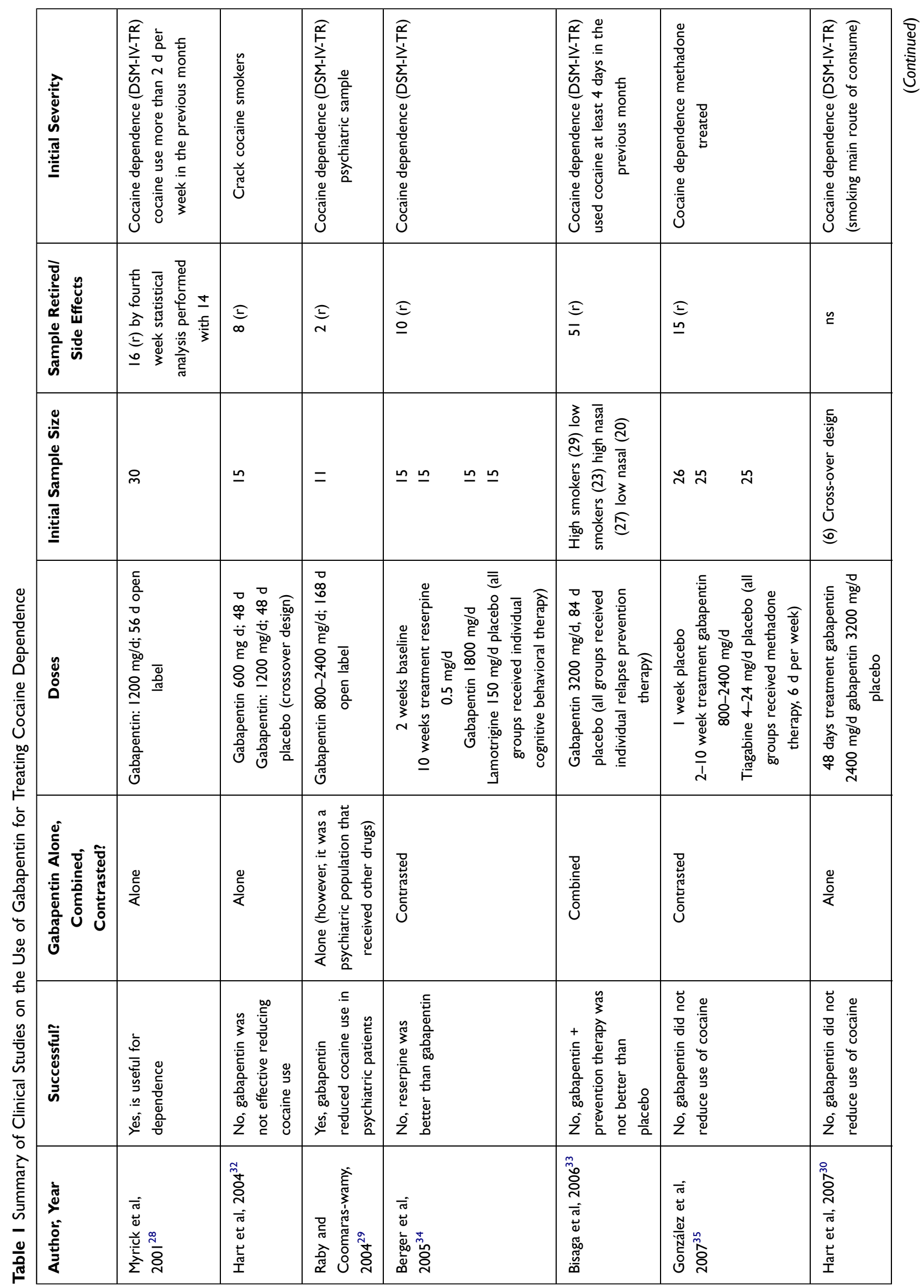



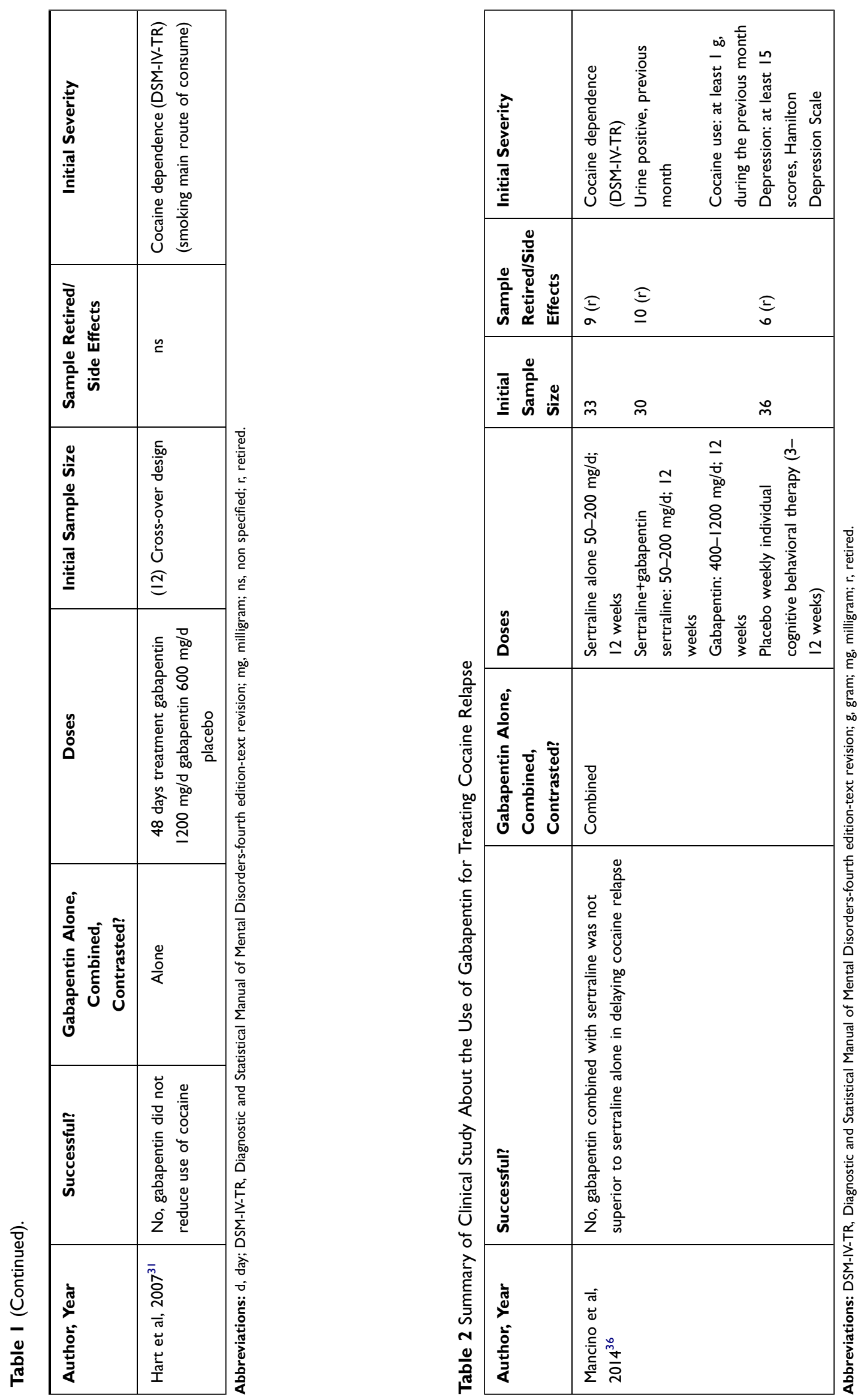


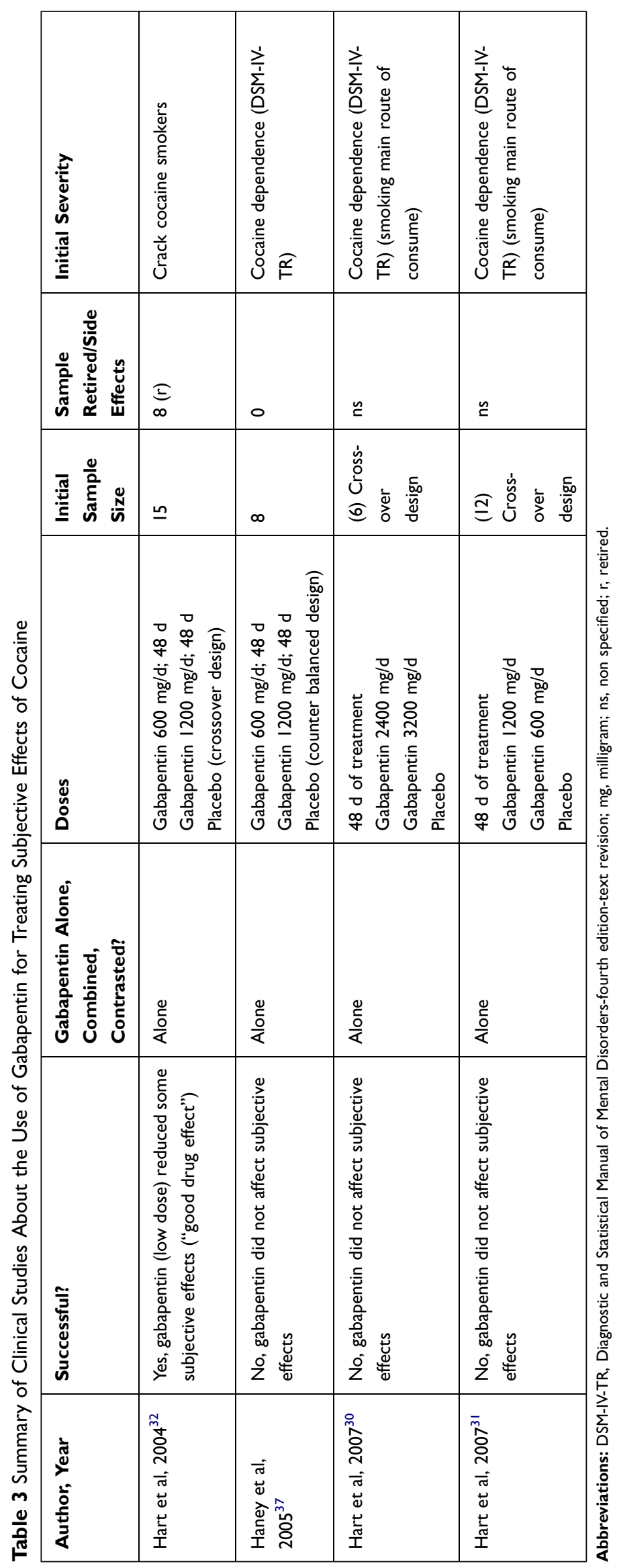




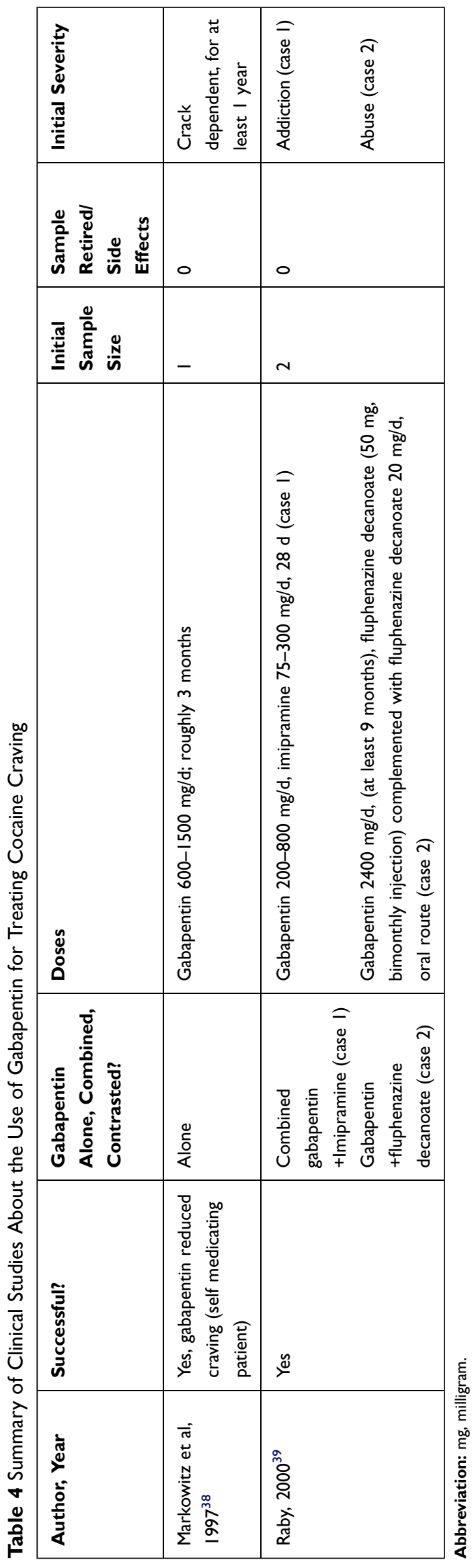

$(100 \%)$ in reduction of cocaine craving. Gabapentin was used alone in one clinical report and in combination in the other report. In the investigation that reported gabapentin uncombined, ${ }^{38}$ the range of doses was $600-1500 \mathrm{mg} / \mathrm{d}$. The administration of the drugs had a total extension of approximately 3 months. This was a clinical report of a single subject $(\mathrm{n}=1)$.

The clinical report, which combined gabapentin with other drugs, ${ }^{39}$ utilized a combination of gabapentin plus imipramine (one participant), and the combination of gabapentin and fluphenazine decanoate (another participant). The participants treated with the combination of the drugs received $200-800 \mathrm{mg} / \mathrm{d}$ of gabapentin, and $75-300 \mathrm{mg} / \mathrm{d}$ of imipramine. The treatment lasted a total of 28 days. The doses employed in the mix of gabapentin with fluphenazine decanoate were: $2400 \mathrm{mg} / \mathrm{d}$ of gabapentin (approximately at least 9 months), bimonthly injections of $50 \mathrm{mg}$ of fluphenazine decanoate, and complemented with $20 \mathrm{mg} / \mathrm{d}$ of oral fluphenazine decanoate. The sample size for each condition was one subject (a total of two subjects).

\section{Animal Studies on the Use of Gabapentin for Treating Cocaine Relapse}

The main points of this section are provided in Table 5 . Gabapentin was employed in a total of 3 studies between 2007 and 2014, with one study reporting reducing cocaine relapse following gabapentin (33.3\% success).

Two researches explored gabapentin alone (without any other drug), and in the other research gabapentin was compared against other drugs (tiagabine and vigabatrin). With respect to the two studies that explored gabapentin alone (without any other drug), one of the studies reported successful results, ${ }^{40}$ and the other reported failure. ${ }^{41}$ In the research that report success, gabapentin was injected bilaterally into the nucleus accumbens core of male Sprague Dawley rats $(225-250 \mathrm{~g}){ }^{40}$ The Gabapentin doses administered were $10-33 \mathrm{ug} / 0.5 \mathrm{uL}$, and following a crossover design (all the doses were administered 10 min before the start of the reinstatement test). The study also included a vehicle control group. Cocaine dependence in rats was produced following infusions of $0.2 \mathrm{mg} / 0.05 \mathrm{~mL}$ of cocaine in FR1 reinforcement (cocaine infusions were associated with light and sound cues). Subsequently, rats were subjected to an extinction phase, in which the cocaine-seeking behavior was reinstated by administering cocaine priming 


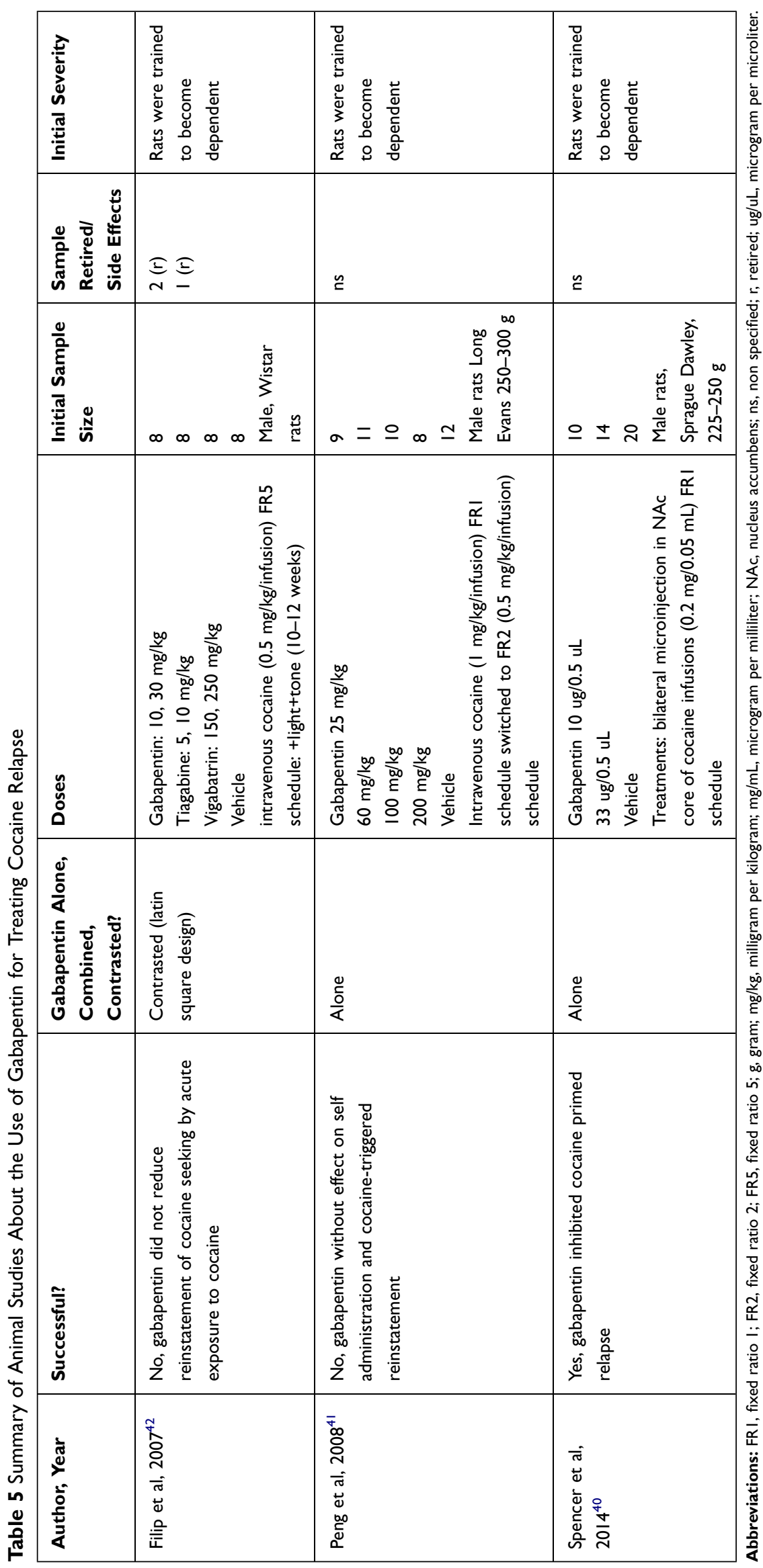


$(10 \mathrm{mg} / \mathrm{kg}$, ip). The sample size of the investigation was 44 animals (14-20 animals per group).

In the study that reported failure, ${ }^{41}$ male Long Evan rats received $25,60,150$ or $250 \mathrm{mg} / \mathrm{kg}$ of gabapentin, with all doses administered either $30 \mathrm{~min}$ or $2 \mathrm{~h}$ before the start of the reinstatement test. A vehicle control group was also included. In this study cocaine dependence was induced by infusion of $1 \mathrm{mg} / \mathrm{kg}$ of cocaine in FR1 reinforcement schedule, and then switched to $0.5 \mathrm{mg} / \mathrm{kg} /$ infusion of cocaine under a FR2 reinforcement (in both ratios cocaine infusions were associated with light and sound cues). Subsequently, rats were subjected to an extinction phase; in which cocaine-seeking behavior was reinstated following administration of a cocaine priming dose of $10 \mathrm{mg} / \mathrm{kg}$ (ip). The sample size for this study was 50 animals (8-12 animals per group).

One study compared gabapentin against other drugs in male Wistar rats. ${ }^{42}$ This study compared gabapentin to tiagabine and vigabatrin. It reported that gabapentin did not reduce the reinstatement of cocaine seeking by acute exposure to cocaine. The rats received one of the following treatments using a Latin square design: 10 or $30 \mathrm{mg} / \mathrm{kg}$ of gabapentin ( $60 \mathrm{~min}$ before the start of the reinstatement test), 5 or $10 \mathrm{mg} / \mathrm{kg}$ of tiagabine (30 min before the start of the reinstatement test), 150 or $250 \mathrm{mg} / \mathrm{kg}$ of vigabatrin (240 min before the start of the reinstatement test), or vehicle only (controls). Dependency to cocaine was induced following $0.5 \mathrm{mg} / \mathrm{kg} /$ infusion of cocaine in a FR5 schedule (+light +tone). Following an extinction phase, the cocaine-seeking behavior was reinstated by cocaine priming $(10 \mathrm{mg} / \mathrm{kg}$, ip). The initial sample size of the research was 32 animals (eight per group), with three omitted from the final analysis (two from the gabapentin cluster, and one from the tiagabine cluster).

\section{Animal Studies on the Use of Gabapentin for Treating Cocaine Dependence}

The main points of this section are provided in Table 6 . Gabapentin was employed in a total of two works between the years 2007 and 2008, with both studies reporting a failure of gabapentin in reducing cocaine self administration ( $0 \%$ success).

One investigation used gabapentin alone (without any other drug), and the other research compared gabapentin against other drugs (tiagabine and vigabatrin). With respect to the investigation that explored gabapentin alone (uncombined), gabapentin did not reduce cocaine self administration. ${ }^{41}$ The study used male Long Evan rats and received one of the following treatments of gabapentin: $25,60,150$ or $250 \mathrm{mg} / \mathrm{kg}$ (all the doses were administered $30 \mathrm{~min}$ or $2 \mathrm{~h}$ before the start of the reinstatement test) or vehicle only. Dependence on cocaine was induced following an infusion of $1 \mathrm{mg} / \mathrm{kg} /$ infusion of cocaine in a FR1 reinforcement, followed by $0.5 \mathrm{mg} / \mathrm{kg} /$ infusion of cocaine under a FR2 reinforcement (in both ratios cocaine infusions were associated with light and sound cues). Following an extinction phase, the cocaineseeking behavior was reinstated by cocaine priming (10 $\mathrm{mg} / \mathrm{kg}$, ip). The sample size of the investigation was 50 animals (8-12 animals per group).

The remaining study compared gabapentin against other drugs (tiagabine and vigabatrin) in male Wistar rats. ${ }^{42}$ This study reported that gabapentin did not reduce cocaine self-administration. The rodents received one of the following regimens: 10 or $30 \mathrm{mg} / \mathrm{kg}$ of gabapentin ( $60 \mathrm{~min}$ before the start of the reinstatement test), 5 or $10 \mathrm{mg} / \mathrm{kg}$ of tiagabine (30 $\mathrm{min}$ before the start of the reinstatement test), and 150 or $250 \mathrm{mg} / \mathrm{kg}$ of vigabatrin (240 $\mathrm{min}$ before the start of the reinstatement test). Dependency on cocaine in the rodents was induced following a $0.5 \mathrm{mg} / \mathrm{kg} /$ infusion of cocaine in a FR5 schedule (+light+tone). The initial sample size of the study was 24 animals (eight per group), with two animals in the gabapentin group omitted from the final analysis.

\section{Animal Study on the Use of Gabapentin for Treating Cocaine Intoxication}

The main points of this section are provided in Table 7 . Gabapentin was used in one study and reported the success of gabapentin for alleviating cocaine intoxication. ${ }^{43}$ Gabapentin was used alone (not combined with other drug) and compared with other drugs, which were also successful in reducing cocaine intoxication: felbamate, loreclezole, losigamone, progabide, remacemide, stiripentol, tiagabine, and vigabatrin. By contrast, clobazam, flunarizine, lamotrigine, topiramate, and zonisamide did not alleviate cocaine intoxication.

The gabapentin doses were: $1,10,30$, or $100 \mathrm{mg} / \mathrm{kg}$ (ip), with a pretreatment time of $60 \mathrm{~min}$. The pretreatment times for the other drugs were in the range of 30 to $60 \mathrm{~min}$, with the exception of topiramate $(15 \mathrm{~min})$ and zonisamide (60 min). In this study, cocaine intoxication was induced in male Swiss-Webster mice following a single dose of 


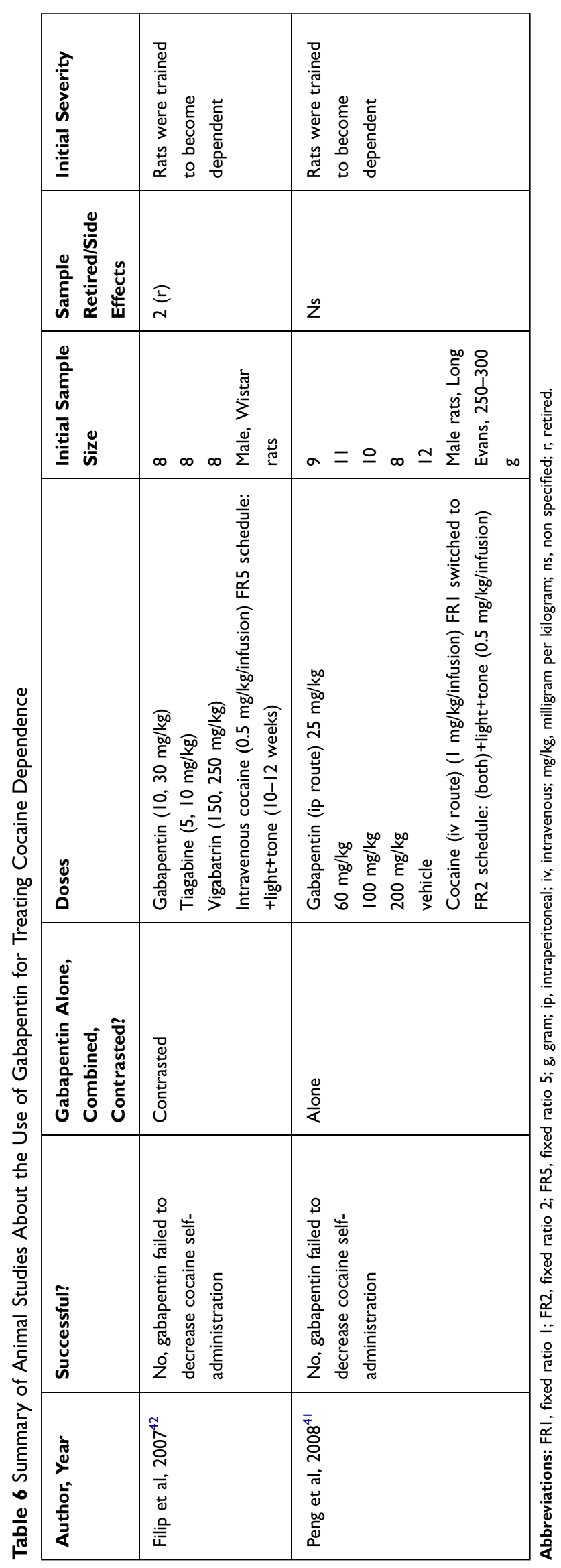




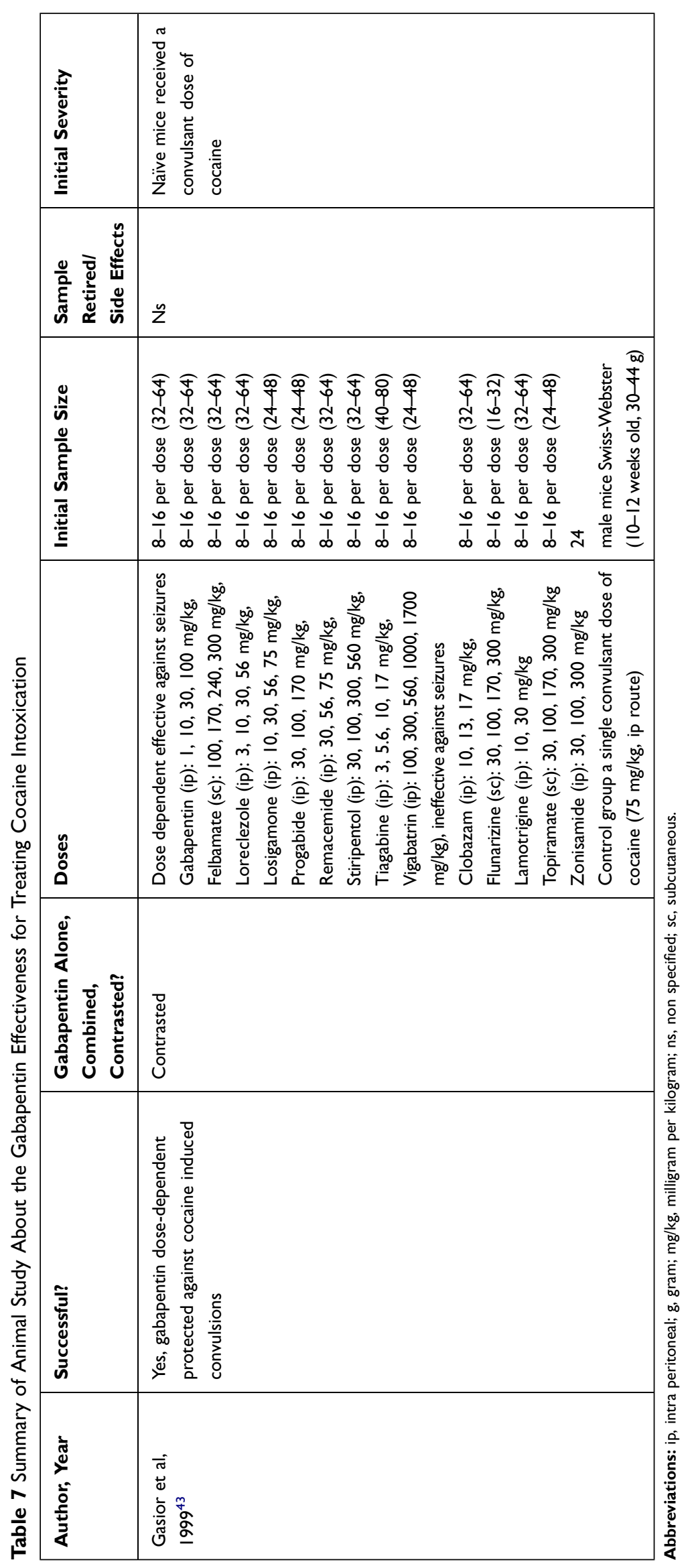


cocaine $(75 \mathrm{mg} / \mathrm{kg}$, ip). Each dose group was composed of eight to 16 mice.

\section{Discussion}

Among the limitations of this review is the small sample size reported in some of the studies. The small sample size used in these studies could explain the failure of gabapentin effectiveness. For instance: a) one study used a sample size of six, and found a lack of gabapentin's effectiveness for treating cocaine dependence. ${ }^{30}$ b) Another study reported gabapentin failure in reducing subjective effects of cocaine, and used a small sample size (six), and this could explain the lack of gabapentin effectiveness. ${ }^{30} \mathrm{c}$ ) The two clinical studies that reported gabapentin effectiveness for reducing cocaine craving were based on very low samples size $(n=1$ and $n=2) ;{ }^{38,39}$ hence, the results should be accepted with caution. On the other hand, rodent studies used an adequate sample size per experimental group: a) 14 to 20 rodents, ${ }^{40}$ b) 8 to 12 rodents, ${ }^{41}$ c) 8 rodents (two animals retired from the gabapentin and one from the tiagabine groups), ${ }^{42}$ and d) 8 to 16 rodents. ${ }^{43}$ Hence, no problem seems to be derived from the sample size of rodent studies. The limitations initially described suggest that further clinical studies on the use of gabapentin in treating cocaine problems should include larger samples to allow more generalizable results.

Another limitation of this review is the absence of multiple studies for confirming a specific tendency, specifically: a) only one clinical study evaluated the use of gabapentin in treating cocaine relapse, ${ }^{36}$ and b) only two clinical works tested gabapentin for treating cocaine craving; ${ }^{38,39}$ therefore, the respective clinical findings should be accepted with caution. Regarding rodent studies, similar limitations were also found: a) only two investigations investigated the use of gabapentin for treating cocaine dependence, ${ }^{41,42}$ and b) only one study tested gabapentin for alleviating cocaine intoxication. ${ }^{43}$ Based on these limitations on the number of studies, further clinical investigations are necessary about the use of gabapentin in treating cocaine relapse and craving; moreover, more rodent studies are needed regarding gabapentin effectiveness in alleviating cocaine dependence and intoxication.

Regarding the clinical studies about the use of gabapentin for treating cocaine dependence, it was only obtained a $25 \%$ of success ( 2 out of 8 studies). Rodent studies (two) do not support the use of gabapentin for alleviating cocaine dependence (self administration model). ${ }^{41,42}$ The two clinical studies that found a successful result employed gabapentin without any other drug (non combined). ${ }^{28,29}$ The only evident differences between these successful studies and those that also used gabapentin alone but failed, ${ }^{30-32}$ are the number of days in treatment ( $56 \mathrm{~d}, 168 \mathrm{~d}$ versus $48 \mathrm{~d}$ ), and the final sample sizes ( 9 and 30 versus, 6, 7 and 8) that were larger in the successful studies. There is no difference regarding doses; successful studies doses $\left(800-2400 \mathrm{mg} / \mathrm{d}^{29}\right.$ and $1200 \mathrm{mg} / \mathrm{d})^{28}$ were very similar to failed studies doses $(0$ placebo, $2400 \mathrm{mg} / \mathrm{d}$, and $3200 \mathrm{mg} / \mathrm{d} ;{ }^{30} 0$ placebo, $600 \mathrm{mg} /$ $\mathrm{d}$, and $1200 \mathrm{mg} / \mathrm{d}) .{ }^{31,32}$

Comparing these findings with a more recent systematic review and meta-analysis work on different treatments for cocaine use disorder, ${ }^{44}$ this recent work found that anticonvulsant and muscle relaxants (gabapentin, baclofen, carbamazepine, lamotrigine, phenytoin, tiagabine, topiramate, and vigabatrin) are not different from placebo for retention or cocaine use. Moreover, this recent study reported that across all anticonvulsants and muscle relaxants as a class, there is insufficient evidence to form conclusions about the effects on abstinence, no difference from placebo on cocaine use and study retention, and insufficient evidence on harms. The present review is consistent with Chan et al, 2019 regarding the absence of solid evidence supporting the use of gabapentin for treating cocaine use disorders. ${ }^{44}$

Another recent systematic review by Saeed et al concluded that no significant benefit of gabapentin was conclusively observed for the treatment of cocaine abuse; ${ }^{45}$ that review evaluated six studies, and the majority of these trials found no significant benefit of gabapentin treatment contrasted with placebo or other drugs evaluated regarding the rate of abstinence achievement, retention in treatment, degree of craving, or probability of future cocaine consumption. The findings of the present review are in agreement with those of Saeed et al, ${ }^{45}$ in that the majority of the studies reviewed do not support the benefit of gabapentin for treating cocaine use problems.

On the other hand, although clinical research does not support the use of gabapentin for treating cocaine relapse,${ }^{36}$ a single rodent study (out of three) found that gabapentin helps with cocaine relapse. ${ }^{40}$ This study used a direct injection in the brain (nucleus accumbens), easing the direct access of gabapentin in the brain. Although this strategy has obvious limitations in the clinical setting, this finding supports further investigation of the use of medicines that are similar to gabapentin (like pregabalin), 
but that can be administered on more standard clinical routes. In effect, pregabalin has some advantages over gabapentin by using more conventional human routes of administration (eg, oral) rather than brain injection. Nonetheless, there are currently not enough studies (clinical or rodent) supporting the use of gabapentin for alleviating cocaine relapse.

Only one out of four clinical studies found gabapentin alone (not combined) success for treating some of the subjective effects of cocaine. ${ }^{32}$ However, these four studies used a relatively low sample $\left[15\right.$ (8 retired), ${ }^{32} 8,{ }^{37} 6,{ }^{30}$ and $12^{31} \mathrm{]}$. Moreover, the findings do not support the use of any specific dose of gabapentin (low dose $-600 \mathrm{mg} / \mathrm{d}$ resulted in one study, ${ }^{32}$ but not in others). ${ }^{31,37}$ Hence, future studies to test gabapentin for alleviating cocaine subjective effects, should combined gabapentin with other drugs, use larger samples, and a broad spectrum of doses. At this point, the examination of recent publications does not support the use of gabapentin in combined fashion for treating subjective effects of cocaine.

Few clinical studies support the use of gabapentin for treating cocaine craving (two). ${ }^{38,39}$ These studies used a very small sample ( $\mathrm{n}=1$ and 2 ). Also, one study used gabapentin alone, ${ }^{38}$ and the other combined (imipramine or fluphenazine decanoate). ${ }^{39}$ The temporal treatment frame ( $28 \mathrm{~d}$ to 9 months) and range of doses (200-1500 $\mathrm{mg} / \mathrm{d}$ of gabapentin) were also different. Given the low number of favorable studies, low samples sizes, broad range of doses and time frames for treatment, and the use of gabapentin alone or combined, there is no firm evidence for recommending gabapentin for treating cocaine relapse. Additional studies therefore required that include larger samples, compare systematically gabapentin alone versus combined with other drugs (at least imipramine or fluphenazine decanoate), cognitive behavioral therapy, and different treatment duration and doses frames (for example, low/short, mid and high/long).

Currently, the evidence supporting gabapentin use for cocaine intoxication is scarce, with one study reported gabapentin for treating cocaine intoxication, and was performed in rodents; ${ }^{43}$ Review of most recent work in the field, an online work, does not mention gabapentin as treatment. $^{46}$ Based on the current findings, it is recommended additional clinical and rodent research, using large samples, and tentatively comparing gabapentin with other successful drugs, ${ }^{43}$ including felbamate, loreclezole, losigamone, progabide, remacemide, stiripentol, tiagabine, and vigabatrin. Please see Table 7 for suggested starting doses for rodent studies.

\section{Conclusion}

\section{Clinical Studies}

Gabapentin has been successful in suppressing cocaine dependence in $25 \%$ of the clinical studies (2/8). In addition, one clinical study has explored gabapentin for treating cocaine relapse and reported a negative result. One out of four clinical studies (25\%) reported gabapentin effectiveness in alleviating the subjective effects of cocaine. Moreover, two clinical studies reported that gabapentin was successful in alleviating cocaine cravings problems. Based on the current findings, it does not support the use of gabapentin for treating the diverse cocaine-related problems covered in this work (dependence, relapse, subjective effects of cocaine, and cravings) because of a lower percentage of successful or insufficient number of studies.

\section{Animal Studies}

There is a $33.33 \%$ of success ( 1 out of 3 investigations) regarding the use of gabapentin for alleviating cocaine relapse. Two rodent investigations reported gabapentin failure to cure cocaine dependence. On the other hand, another rodent study reported gabapentin effectiveness for treating epilepsy induced by cocaine; more studies are needed to support this finding. Based on the rodent research related in this field, there is no firm evidence to support the use of gabapentin for treating cocaine dependence, relapse, and seizure problems because of the lower percentages of success and insufficient number of studies.

\section{Clinical and Animal Studies's Conclusions Integrated}

Gabapentin is not useful for alleviating cocaine dependence $(20 \%$ of success in 10 studies), or relapse $(25 \%$ success in four studies). No report exists regarding animal research assessing gabapentin treatment for the subjective effects of cocaine; however, based on human studies, gabapentin failed to alleviate subjective effects of cocaine (25\% success in four studies). One rodent study has reported the usefulness of gabapentin for alleviating cocaine intoxication (epilepsy), but there is an absence of clinical counterpart studies. More research is necessary to confirm if gabapentin is useful for treating cocaine intoxication. Two clinical investigations have informed the utility of gabapentin for treating cocaine cravings, but 
there is an absence of animal complementary research and more investigation is required to support the use of gabapentin for treating cocaine cravings.

\section{Acknowledgments}

I would like to thank the Open Access Publishing Fund from Florida State University Libraries for it's funding. Dr. G. Quintero Garzola was partially backed until 2019 by the SNI (Sistema Nacional de Investigacion) from SENACYT. SENACYT is a public organization located in Panama. Thanks to Dr. Anthony L. Vaccarino (Indoc Research, Toronto, Canada) for English editing corrections to the manuscript. The author is now also affiliated with the Center for Population Sciences and Healthy Equity of the Florida State University.

\section{Disclosure}

The author reports no conflicts of interest in this work.

\section{References}

1. National Center for Biotechnology Information. Pub chem substance database. Bethesda, USA: U.S. National Library of Medicine; December 1, 2016. Available from: https://pubchem.ncbi.nlm.nih. gov/substance/46506529D. Accessed January 5, 2018.

2. Drug Information Portal. Search drug information portal. Bethesda, USA: U.S. National Library of Medicine; April 1, 2016. Available from: https:// druginfo.nlm.nih.gov/drugportal/name/Gabapentin. Accessed January 5, 2018.

3. Bockbrader HN, Wesche D, Miller R, Chapel S, Janiczek N, Burger P. A comparison of the pharmacokinetics and pharmacodynamics of pregabalin and gabapentin. Clin Pharmacokinet. 2010;49(10):661669. doi: $10.2165 / 11536200-000000000-00000$

4. Hengy H, Kolle E-U. Determination of gabapentin in plasma and urine by high-performance liquid chromatography and pre-column labelling for ultraviolet detection. J Chromatogr. 1985;341(2):473478. doi:10.1016/S0378-4347(00)84064-5

5. Reimann W. Inhibition by GABA, baclofen and gabapentin of dopamine release from rabbit caudate nucleus: are there common or different sites of action? Eur J Pharmacol. 1983;94(3-4):341-344. doi:10.1016/0014-2999(83)90425-9

6. Schlicker E, Reimann W, Gothert M. Gabapentin decreases monoamine release without affecting acetylcholine release in the brain Arzneimittelforschung. 1985;35(9):1347-1349.

7. Vollmer KO, von Hodenberg A, Kolle EU. Pharmacokinetics and metabolism of gabapentin in rat, dog and man. Arzneimittelforschung. 1986;36(5):830-839.

8. Bartoszyk GD, Hamer M. The genetic animal model of reflex epilepsy in the Mongolian gerbil: differential efficacy of new anticonvulsive drugs and prototype antiepileptics. Pharmacol Res Commun. 1987;19(6):429-440. doi:10.1016/0031-6989(87)90082-8

9. Crawford P, Ghadiali E, Lane R, Blumhardt L, Chadwick D. Gabapentin as an antiepileptic drug in man. J Neurol Neurosurg Psychiatry. 1987;50(6):682-686. doi:10.1136/jnnp.50.6.682

10. Ryback R, Ryback L. Gabapentin for behavioral dyscontrol. Am J Psychiatry. 1995;152(9):1399. doi:10.1176/ajp.152.9.1399a

11. Walden J, Hesslinger B. Value of old and new anticonvulsants in treatment of psychiatric diseases. Fortschr Neurol Psychiatr. 1995;63 (8):320-335. doi:10.1055/s-2007-996633
12. Welty DF, Schielke GP, Rothstein JD. Potential treatment of amyotrophic lateral sclerosis with gabapentin: a hypothesis. Ann Pharmacother. 1995;29(11):1164-1167. doi:10.1177/106002809502901118

13. Rosner H, Rubin L, Kestenbaum A. Gabapentin adjunctive therapy in neuropathic pain states. Clin J Pain. 1996;12(1):56-58. doi:10.1097/ 00002508-199603000-00010

14. Shimoyama M, Shimoyama N, Inturrisi CE, Elliott KJ. Gabapentin enhances the antinociceptive effects of spinal morphine in the rat tailflick test. Pain. 1997;72(3):375-382. doi:10.1016/s0304-3959(97) 00065-1

15. Singh L, Field MJ, Ferris P, et al. The antiepileptic agent gabapentin (neurontin) possesses anxiolytic-like and antinociceptive actions that are reversed by D-serine. Psychopharmacology. 1996;127(1):1-9. doi: $10.1007 / \mathrm{bf} 02805968$

16. Segal AZ, Rordorf G. Gabapentin as a novel treatment for postherpetic neuralgia. Neurology. 1996;46(4):1175-1176. doi:10.1212/wnl.46.4.1175

17. Adler CH. Treatment of restless legs syndrome with gabapentin. Clin Neuropharmacol. 1997;20(2):148-151. doi:10.1097/00002826-19970 4000-00006

18. Mellick GA, Mellick LB. Management of restless legs syndrome with gabapentin (neurontin). Sleep. 1996;19(3):224-226. doi:10.1093/sleep/ 19.3.224

19. Ryback RS, Brodsky L, Munasifi F. Gabapentin in bipolar disorder. $J$ Neuropsychiatry Clin Neurosci. 1997;9(2):301. doi:10.1176/jnp.9.2.301b

20. Gass JT, Olive MF. Glutamatergic substrates of drug addiction and alcoholism. Biochem Pharmacol. 2008;75(1):218-265. doi:10.1016/j. bcp.2007.06.039

21. Minozzi S, Amato L, Davoli M, et al. Anticonvulsants for cocaine dependence. Cochrane Database Syst Rev. 2008;16(2):CD006754. doi:10.1002/14651858.CD006754.pub2

22. Minozzi S, Cinquini M, Amato L, et al. Anticonvulsants for cocaine dependence. Cochrane Database Syst Rev. 2015;17(4):CD006754. doi:10.1002/14651858.CD006754.pub4

23. Olive MF, Cleva RM, Kalivas PW, Malcolm RJ. Glutamatergic medications for the treatment of drug and behavioral addictions. Pharmacol Biochem Behav. 2012;100(4):801-810. doi:10.1016/j. pbb.2011.04.015

24. Zullino DF, Khazaal Y, Hättenschwiler J, Borgeat F, Besson J. Anticonvulsant drugs in the treatment of substance withdrawal. Drugs Today. 2004;40(7):603-619. doi:10.1358/dot.2004.40.7.850478

25. Berlin RK, Butler PM, Perloff MD. Gabapentin therapy in psychiatric disorders: a systematic review. Prim Care Companion CNS Disord. 2015;17(5). doi:10.4088/PCC.15r01821

26. Howland RH. Gabapentin for the treatment of substance use disorders. J Psychosoc Nurs Ment Health Serv. 2013;51(12):11-14. doi:10.3928/02793695-20131120-01

27. Magnus L. Nonepileptic uses of gabapentin. Epilepsia. 1999;40(Suppl6): S66-S72; discussionS73-64. doi:10.1111/j.1528-1157.1999.tb00936.x

28. Myrick H, Henderson S, Brady KT, Malcolm R. Gabapentin in the treatment of cocaine dependence: a case series. J Clin Psychiatry. 2001;62(1):19-23. doi:10.4088/jcp.v62n0105

29. Raby WN, Coomaraswamy S. Gabapentin reduces cocaine use among addicts from a community clinic sample. J Clin Psychiatry. 2004;65(1):84-86. doi:10.4088/jcp.v65n0114

30. Hart CL, Haney M, Collins ED, Rubin E, Foltin RW. Smoked cocaine self-administration by humans is not reduced by large gabapentin maintenance doses. Drug Alcohol Depend. 2007;86(2-3):274277. doi:10.1016/j.drugalcdep.2006.05.028

31. Hart CL, Haney M, Vosburg SK, Rubin E, Foltin RW. Gabapentin does not reduce smoked cocaine self-administration: employment of a novel self-administration procedure. Behav Pharmacol. 2007;18 (1):71-75. doi:10.1097/FBP.0b013e328014139d

32. Hart CL, Ward AS, Collins ED, Haney M, Foltin RW. Gabapentin maintenance decreases smoked cocaine-related subjective effects, but not self-administration by humans. Drug Alcohol Depend. 2004;73 (3):279-287. doi:10.1016/j.drugalcdep.2003.10.015 
33. Bisaga A, Aharonovich E, Garawi F, et al. A randomized placebocontrolled trial of gabapentin for cocaine dependence. Drug Alcohol Depend. 2006;81(3):267-274. doi:10.1016/j.drugalcdep.2005.07.009

34. Berger SP, Winhusen TM, Somoza EC, et al. A medication screening trial evaluation of reserpine, gabapentin and lamotrigine pharmacotherapy of cocaine dependence. Addiction. 2005;100(Suppl1):5867. doi:10.1111/j.1360-0443.2005.00983.x

35. González G, Desai R, Sofuoglua M, et al. Clinical efficacy of gabapentin versus tiagabine for reducing cocaine use among cocaine dependent methadone-treated patients. Drug Alcohol Depend. 2007;87(1):1-9. doi:10.1016/j.drugalcdep.2006.07.003

36. Mancino MJ, McGaugh J, Chopra MP, et al. Clinical efficacy of sertraline alone and augmented with gabapentin in recently abstinent cocainedependent patients with depressive symptoms. J Clin Psychopharmacol. 2014;34(2):234-239. doi:10.1097/jcp.0000000000000062

37. Haney M, Hart C, Collins ED, Foltin RW. Smoked cocaine discrimination in humans: effects of gabapentin. Drug Alcohol Depend. 2005;80(1):53-61. doi:10.1016/j.drugalcdep.2005.03.006

38. Markowitz JS, Finkenbine R, Myrick H, Lunsford K, Carson WH. Gabapentin abuse in a cocaine user: implications for treatment? $J$ Clin Psychopharmacol. 1997;17(5):423-424. doi:10.1097/00004714199710000-00012

39. Raby WN. Gabapentin therapy for cocaine cravings. Am J Psychiatry. 2000;157(12):2058-2059. doi:10.1176/appi.ajp.157.12.2058-a
40. Spencer S, Brown RM, Quintero GC, et al. Alpha2delta-1 signaling in nucleus accumbens is necessary for cocaine-induced relapse. J Neurosci. 2014;34(25):8605-8611. doi:10.1523/jneurosci.1204-13.2014

41. Peng XQ, Li X, Li J, et al. Effects of gabapentin on cocaine selfadministration, cocaine triggered relapse and cocaine-enhanced nucleus accumbens dopamine in rats. Drug Alcohol Depend. 2008;97(3):207-215. doi:10.1016/j.drugalcdep.2007.09.019

42. Filip M, Frankowska M, Zaniewska M, Gołda A, Przegaliński E, Vetulani J. Diverse effects of GABA-mimetic drugs on cocaineevoked self-administration and discriminative stimulus effects in rats. Psychopharmacology. 2007;192(1):17-26. doi:10.1007/s00213006-0694-7

43. Gasior M, Ungard JT, Witkin JM. Preclinical evaluation of newly approved and potential antiepileptic drugs against cocaine-induced seizures. J Pharmacol Exp Ther. 1999;290(3):1148-1156.

44. Chan B, Kondo K, Freeman M, Ayers C, Montgomery J, Kansagara D. Pharmacotherapy for cocaine use disorder-a systematic review and meta-analysis. J Gen Intern Med. 2019;34(12):2858-2873. doi:10.1007/s11606-019-05074-8

45. Saeed A, Ramya B, Padma K, et al. Use of gabapentin in the treatment of substance use and psychiatric disorders: a systematic review. Front Psychiatry. 2019;10:228. doi:10.3389/fpsyt.2019.00228

46. Richards JR, Le JK. Cocaine Toxicity. StatPearls. Treasure Island (FL): StatsPearls Publishing; 2020.
Open Access Journal of Clinical Trials

\section{Publish your work in this journal}

The Open Access Journal of Clinical Trials is an international, peerreviewed, open access journal publishing original research, reports, editorials, reviews and commentaries on all aspects of clinical trial design, management, legal, ethical and regulatory issues, case record form design, data collection, quality assurance and data auditing

\section{Dovepress}

methodologies. The manuscript management system is completely online and includes a very quick and fair peer-review system, which is all easy to use. Visit http://www.dovepress.com/testimonials.php to read real quotes from published authors. 